\title{
Volumetric Modulated Arc Therapy versus Conventional Radiotherapy of Early Testicular Seminoma Irradiation: Dosimetric Study
}

\author{
MW Hegazy ${ }^{1,2^{*}}$ (D) and O Hassad ${ }^{3}$ \\ ${ }^{1}$ Section of Radiation Oncology, King Faisal Specialist Hospital \& Research Centre, Saudi Arabia \\ ${ }^{2}$ Department of Clinical Oncology \& Nuclear Medicine, Zagazig College of Medicine, Egypt \\ ${ }^{3}$ Department of Biomedical Physics, King Faisal Specialist Hospital and Research Centre, Saudi Arabia
}

*Corresponding author: Mohamed Wahba Hegazy, Department of Clinical Oncology and Nuclear Medicine, King Faisal Specialist Hospital \& Research Centre, Medicine College, Zagazig University, Egypt, Tel: +201090063872

\begin{abstract}
Background: Testicular tumor is a rare tumor in men. Testicular seminoma is less aggressive than nonseminoma of germ cell tumors. Adjuvant nodal irradiation is an option of early stages I, IIA and IIB $\leq 3 \mathrm{~cm}$ pure seminoma disease. The aim of this study was to investigate which radiotherapy technique is better in nodal irradiation of early stage II pure seminoma, 3D-CRT or VMAT.
\end{abstract}

Methods: This study was done on 5 patients with pure seminoma diagnosed at king Faisal Specialist Hospital \& Research Center, Riyadh, Saudi Arabia; all are planned for postoperative radiation therapy with prescribed dose of 30$36 \mathrm{~Gy}$ in 15-18 fractions according to nodal size.

Results: Both techniques achieved comparable target coverage; however VMAT had better dose conformity, dose homogeneity and OARs sparingbut with exposing bigger volumes (V5) of normal tissues to lower dose of radiation while $\mathrm{V} 10$ and $\mathrm{V} 15$ are bigger in 3D-CRT.

Conclusion: VMAT is one of the most common techniques used nowadays due to high therapeutic ratio comparable to the conventional technique however low integral dose (V5) is still one of the drawbacks of modern irradiation techniques which are not the case in conventional techniques.

\section{Keywords}

Arc therapy, Conventional radiotherapy, Seminoma

\section{Abbreviations}

3D CRT: 3 Dimensional Conformal radiotherapy; VMAT: Volumetric Modulated Arc Therapy; 4D: Four Dimensional; RAR: Rapid Arc; CT: Computerized Tomography; PET/CT:
Positron emission Tomography/Computerized Tomography; GTV: Gross Target Volume; CTV: Clinical Target Volume; PTV: Planning Target Volume; OARs: Organs at Risk Dose; CI: Conformity Index; HI: Homogeneity Index; IMRT: Intensity Modulated Radiation Therapy

\section{Background}

Testicular tumor is a rare tumor in men and represents less than $1 \%$ with peak incidence between ages 20-34 years [1-7].

Testicular seminoma is less aggressive than nonseminoma of germ cell tumors $[2,8,9]$.

Radical inguinal orchiectomy is the main treatment option of pure testicular seminoma [10].

Adjuvant nodal irradiation is an option of early stages I, $\| A$ and $\| B \leq 3 \mathrm{~cm}$ pure seminoma disease $[11,12]$.

Para aortic lymph nodes are the target volume in stage I, while paraaortic and proximal ipsilateral pelvic nodes are the targets in early stage II of pure seminoma disease [12]. The radiation dose in stage I is $20 \mathrm{~Gy}$ [13] while early stage II is $30-36 \mathrm{~Gy}$ of pure seminoma disease [12].

The aim of this study was to investigatewhich radiotherapy technique is better in nodal irradiation of early stage II pure seminoma, 3D-CRT or VMAT.

Citation: Hegazy MW, Hassad O (2021) Volumetric Modulated Arc Therapy versus Conventional Radiotherapy of Early Testicular Seminoma Irradiation: Dosimetric Study. Int J Cancer Clin Res 8:163. doi. org/10.23937/2378-3419/1410163

Accepted: November 13, 2021: Published: November 15, 2021

Copyright: (C) 2021 Hegazy MW, et al. This is an open-access article distributed under the terms of the Creative Commons Attribution License, which permits unrestricted use, distribution, and reproduction in any medium, provided the original author and source are credited. 
Table 1: Patient's characteristics

\begin{tabular}{|l|c|c|c|c|c|c|c|c|c|c|}
\hline & \multicolumn{2}{|c|}{ Patient 1 } & \multicolumn{2}{c|}{ Patient 2 } & \multicolumn{2}{c|}{ Patient 3 } & \multicolumn{2}{c|}{ Patient 4 } & \multicolumn{2}{c|}{ Patient 5 } \\
\cline { 2 - 12 } & 3D & RA & 3D & RA & 3d & RA & $3 \mathrm{~d}$ & RA & $3 \mathrm{~d}$ & RA \\
\hline PTV & & & & & & & & & & \\
Mn\% & 101.4 & 101 & 102.4 & 101.6 & 102 & 101.5 & 101.5 & 101 & 101.6 & 101.4 \\
Mx \% & 105.8 & 105 & 105 & 104.6 & 106 & 105 & 105.5 & 104.2 & 106.1 & 105 \\
Mm \% & 94 & 91 & 97 & 94 & 90 & 92 & 91 & 93 & 90 & 93 \\
\hline Kidney & & & & & & & & & & \\
Rt Mn \% & 34 & 31.5 & 12.1 & 10.5 & 35 & 32 & 13 & 11 & 38 & 35 \\
Lt Mn \% & 9.8 & 11 & 31.7 & 17.7 & 11 & 12 & 30 & 16 & 12 & 10 \\
Mn both \% & 22 & 21.3 & 21.9 & 14.1 & 23 & 22 & 21.5 & 13.5 & 25 & $\mathbf{2 2 . 5}$ \\
& & & & & & & & & & \\
\hline Spinal cord & 58.5 & 27.1 & 63.5 & 51.9 & 60.5 & 45.1 & 55.4 & 30.2 & 50.3 & $\mathbf{3 0 . 2}$ \\
Mn\% & & & & & & & & & & \\
& & & & & & & & & & \\
\hline Bowel & & & & & & & & & & \\
Mean \% & 21.1 & 22.4 & 34.4 & 24.8 & 25.5 & 26.2 & 40.2 & 28 & 36.7 & $\mathbf{2 6 . 2}$ \\
\hline Body C.C) & & & & & & & & & & \\
V5 & 5990 & 9005 & 6090 & 9210 & 4500 & 8400 & 5600 & 8200 & 4900 & $\mathbf{8 5 0 0}$ \\
V10 & 4980 & 3490 & 5010 & 3450 & 3560 & 2200 & 4550 & 2950 & 3800 & $\mathbf{2 2 5 0}$ \\
V15 & 4505 & 1770 & 4470 & 1630 & 3010 & 1520 & 4010 & 1720 & 3050 & 1450 \\
\hline CI & 0.3 & 0.75 & 0.4 & 0.85 & 0.4 & 0.75 & 0.5 & 0.85 & 0.65 & 0.8 \\
\hline HI & 1.4 & 1.1 & 1.3 & 1.1 & 1.2 & 1.0 & 1.5 & 1.2 & 1.35 & 1.1 \\
\hline
\end{tabular}

\section{Methods}

This study was done on 5 patients with early stage II pure seminoma diagnosed at king Faisal Specialist Hospital \& Research Center, Riyadh, Saudi Arabia, all are planned for postoperative radiation therapy with prescribed dose of 30-36 Gy in 15-18 fractions. In both techniques, we looked at planning target volume coverage, dose homogeneity indices and organs at risk dose (bowel, kidney, spinal cord) and integral dose, Table 1.

\section{CT simulation and contouring}

Planning 4D-CT scan was done by departmental scanner (Philips Medical Systems, Cleveland, $\mathrm{OH}$ ); with a slice thickness of $2.5 \mathrm{~mm}$. Patient's position was supine with arms up and scanned from mid thoracic spine to upper third of both femurs. Penis was put away and contralateral testicle was shielded. Fusion of Planning $\mathrm{CT}$ with $\mathrm{CT}$ and/or PET/CT scans was done to aid intarget contouring of GTV which expanded by $1-2 \mathrm{~cm}$ to create the CTV1 then editing of organs at risk from CTV1 which then expanded $0.5 \mathrm{~cm}$ in all directions to create the PTV1 [14]. PTV1 was received 30-36 Gy in 2 Gy per fraction according to nodal size. CTV2 (modified dogleg field) $[15,16]$ is contouring of vascular structures of retroperitoneal and proximal ipsilateral pelvic areas using brush diameter of $1.5-2 \mathrm{~cm}$ with editing of surrounding organs then adding uniform $0.5 \mathrm{~cm}$ margin in all directions to create PTV2 which received $20 \mathrm{~Gy}$ in 2 Gy per fraction. The upper border of the CTV2 is top of $11^{\text {th }}$ dorsal spine and lower border is top of acetabulum $[12,17]$.

\section{Conventional 3D planning}

We used Eclipse planning system (Varian Medical Systems, Inc., Palo Alto, CA) along with the analytical anisotropic algorithm (Acuros External Beam, Version 13.3.23) dose calculation. The plans were created with mixed $15 \mathrm{MV}$ using anterior/posterior fields with equal weighting.

\section{Rapid Arc}

We used Eclipse planning system with optimization using Progressive Resolution Optimizer (PRO) Version 13.6.23 for VMAT calculation, as far as dose volume dose calculation, Acuros External Beam version 13.6.23 was implemented. All plans generated using True Beam LINACS of $10 \mathrm{MV}$ with 2 arcs (full and/or partial), Arc mode. Arcs had the same Isocenter at the center of the PTV.

\section{Treatment plan evaluation and statistics}

Dose-volume histogram, conformity and homogeneity indices were analyzed to compare treatment plans using Wilcoxon signed rank test (SPSS, V19, USA), a probability value of $<0.05$ considered to be statistically significant (two tailed).

\section{Results}

\section{Target coverage}

Both techniques achieved comparable coverage even the minimum of PTV was similar in both plans, Table 2.

\section{Dosimetric parameters}

VMAT had better and statistically significant $\mathrm{HI}$ and $\mathrm{Cl}$ than 3D-CRT. 
Table 2: Statistical results and $P$ value of both techniques.

\begin{tabular}{|l|l|l|l|}
\hline & 3D & RA & P value \\
\hline PTV & & & \\
Mn & 101.8 & 101.3 & 0.5 \\
Mx & 105.7 & 104.8 & 0.42 \\
Mm & 91.4 & 92.4 & 0.48 \\
& & & \\
\hline Kidney & & & \\
Right & 26.4 & 24 & 0.45 \\
Left & 18.9 & 13.3 & 0.07 \\
Both & 22.7 & 18.7 & 0.08 \\
\hline Spinal cord & 57.6 & 36.9 & $\mathbf{0 . 0 3}$ \\
\hline Bowel & 31.6 & 25.5 & 0.04 \\
\hline Body & & & \\
V5 & 5416 & 8663 & 0.046 \\
V10 & 4380 & 2868 & 0.038 \\
V15 & 3809 & 1618 & $\mathbf{0 . 0 2 8}$ \\
\hline CI & 0.45 & 0.8 & $\mathbf{0 . 0 2 6}$ \\
\hline HI & 1.35 & 1.1 & $\mathbf{0 . 0 3 4}$ \\
\hline
\end{tabular}

$\mathrm{HI}$ of VMAT was 1.1 versus $1.35(p=0.034) \& \mathrm{Cl}$ of VMAT was 0.8 versus $0.45(p=0.026)$, Table 2 .

\section{Organs at risk dose}

Normal tissue sparing was optimal in both techniques however VMAT has statistically significant spinal cord sparing $(p=0.03)$, lower bowel dose $(p=0.04)$ and nonstatistically significant kidney dose, Table 2.

\section{Integral dose}

The body volume received 5Gy (V5) was lower and statistically significant in 3D-CRT $(P=0.46)$ while V10 and V15 were lower and statistically significant in VMAT ( $p=0.038$ and 0.028 respectively), Table 2 .

\section{Discussion}

Most modern techniques of radiotherapy have achieved better target coverage, normal tissue sparing while exposing the bigger volume of tissues to lower doses of irradiation. The usual practice of pure seminoma irradiation in our department to use VMAT technique especially in stages Ila and IIb $\leq 3 \mathrm{~cm}$.

Regarding to tumor coverage, in this study, both plans have optimal and similar target coverage as reported by Zilli, et al. [18] and Hoppe, et al. [19] through using IMRT.

In this study, VMAT achieved more OARs sparing than 3D-CRT especially bowel, spinal cord and kidney as in studies noticed by Zilli, et al. [18] and Hoppe, et al. [19].

The lower integral doses (V10 \& V15) and OARs sparing delivered by modern techniques as in this study may be added to other studies [18-20] to share in lowering the toxicity and decreasing the incidence of expected second malignancies, however better results can be achieved through proton beam technique via more OARs sparing and lowest integral dose so that high therapeutic ratio is achieved which means minimal toxicity score and lower secondary malignancy profiles as reported by different studies however proton therapy is not widespread worldwide [18-21].

One limitation of this study is the small sample size due to the rarity of such cases, however this is the case in dosimetric studies.

\section{Conclusion}

VMAT is one of the most common techniques used nowadays due to high therapeutic ratio comparable to the conventional technique however low integral dose (V5) is still one of the drawbacks of modern irradiation techniques which are not the case in conventional techniques.

\section{Funding and Conflict of Interest}

\section{Ethics approval and consent to participate}

For retrospective review, no consent was required by the ethics committee.

\section{Competing interests}

No conflict of interest.

\section{Funding}

Not applicable.

\section{References}

1. SEER Cancer Statistics Factsheets: Testicular Cancer (2019) National Cancer Institute. Bethesda, MD.

2. Sarici H, Telli O, Eroglu M (2013) Bilateral testicular germ cell tumors. Turk J Urol 39: 249-252.

3. Huyghe E, Matsuda T, Thonneau P (2003) Increasing incidence of testicular cancer world wide: A review. J Urol 170: 5-11.

4. Shanmugalingam $T$, Soultati $A$, Chowdhury $S$, Rudman $S$, Hemelrijck MV, et al. (2013) Global incidence and outcome of testicular cancer. Clin Epidemiol 5: 417-427.

5. Verhoeven RH, Gondos A, Janssen-Heijnen ML, Saum $\mathrm{KU}$, Brewster DH, et al. (2013) Testicular cancer in Europe and the USA: survival still rising among older patients. Ann Oncol 24: 508-513.

6. Chia VM, Quraishi SM, Devesa SS, Purdue MP, Cook MB, et al. (2010) International trends in theincidence of testicular cancer, 1973-2002. Cancer Epidemiol Biomarkers Prev 19: 1151-1159.

7. Pishgar F, Haj-Mirzaian A, Ebrahimi H, Moghaddam SS, Mohajer B, et al. (2019) Global, regional andnational burden of testicular cancer, 1990-2016: Results from the Global Burden of Disease Study 2016. BJU Int 124: 386-394.

8. Vasdev N, Moon A, Thorpe AC (2013) Classification, epidemiology and therapies for testicular germ cell tumours. Int J Dev Biol 57: 133-139.

9. Amin MB, Edge SB, Greene F, et al. (2017) AJCC Cancer Staging Manual. ( $8^{\text {th }}$ edn), New York: Springer International Publishing. 
10. Jones RH, Vasey PA (2003) Part I: Testicular cancermanagement of early disease. Lancet Oncol 4: 730-737.

11. Mead GM, Fossa SD, Oliver RT, Joffe JK, Huddart RA, et al. (2011) Randomized trials in 2466 patients with stage I seminoma: Patterns of relapse and follow-up. J Natl Cancer Inst 103: 241-249.

12. Classen J, Schmidberger $H$, Meisner C, Souchon $R$, Sautter-Bihl ML, et al. (2003) Radiotherapy for stages IIA/B testicular seminoma: Final report of a prospective multicenter clinical trial. J Clin Oncol 21: 1101-1106.

13. Garmezy B, Pagliaro LC (2009) Choosing treatment for stage I seminoma: Who should get what? Oncology (WillistonPark) 23: 753-759.

14. Boujelbene N, Cosinschi A, Boujelbene N, Khanfir K, Bhagwati S, et al. (2011) Pure seminoma: Are view and update. Radiat Oncol 6: 90.

15. Dinniwell R, Chan P, Czarnota G, Haider MA, Jhaveri K, et al. (2009) Pelvic lymphnode topography for radiotherapy treatment planning from ferumoxtran-10 contrast-enhanced magnetic resonance imaging. Int J Radiat Oncol Biol Phys 74: 844-851.

16. Shih HA, Harisinghani $M$, Zietman AL, Wolfgang JA, Saksena M, et al. (2005) Mapping of nodal disease in locally advanced prostate cancer: Rethinking the clinical target volume for pelvic no dalir radiation based on vascular rather than bonyanatomy. Int J Radiat Oncol Biol Phys 63: 1262-1269.

17. Paly JJ, Efstathiou JA, Hedgire SS, Chung PWM, Malley MO, et al. (2013) Mapping patterns of nodal metastases in seminoma: Rethinking radiotherapy fields. Radiother Oncol 106: $64-68$

18. Zilli T, Boudreau C, Doucet R, Alizadeh M, Lambert C, et al. (2011) Bone marrow-sparing intensity-modulated radiation therapy for Stage I seminoma. Acta Oncol 50: 555-562.

19. Hoppe BS, Hunter MM, Mendenhall NP, Li Z, Indelicato DJ (2013) Improving the therapeutic ratio by using proton therapy in patients with stage I or II seminoma; Am J Clin Oncol 36: 213-214.

20. Efstathiou JA, Paly JJ, Lu HM, Athar BS, Moteabbed M, et al. (2012) Adjuvant radiation therapy for early stage seminoma: proton versus photon planning comparison and modeling of second cancer risk. Radiother Oncol 103: 1217.

21. Hall EJ, Wuu CS (2003) Radiation-induced second cancers: the impact of 3D-CRT and IMRT. Int J Radiat Oncol Biol Phys 56: 83-88. 